\title{
HELICOID STAIR ANALYSIS BY SEMILOOF BEAM ELEMENT FOR DIFFERENT LOADINGS
}

\author{
Dr. Vikas Gandhe \\ Professor, SOA IPS Academy Indore (M.P), INDIA
}

\begin{abstract}
The paper presents the analysis of special curved structure, which is curved not only in plan but curved in elevation also. Such type of is helicoid stair. This staircase was analyzed by using finite element method. The isoparametric curved beam element is capable of modelling the curvature in plan and in elevation. The stresses were predicted along the centerline of curved length The helicoid staircase with 90 degree helix angle, was discretized with six curved elements with13 nodal points and maximum 31 degree of freedom. Displacements in $u v$ and $w$ directions, stress resultants and inplane moments were predicted for four types of loading .(1:): u d l over an entire length . (2) u d l over bottom half length (3) u d l over top half length (4) Point loads at quarter lengths Other parameters considered were waist slab thickness : $200 \mathrm{~mm}$, floor height : $3.2 \mathrm{~m}$, inner radius : $500 \mathrm{~mm}$, outer radius : $1500 \mathrm{~mm}$., with restrained top and bottom supports.The results thus obtained were shown graphically as well as in a tabular form. The salient values for displacements, stress resultants, and moments were also shown in a tabular form.
\end{abstract}

Keywords: Discritize, finite Element Method, gaussian points, Isoparametric Element, Loof nodes

Cite this Article: Dr. Vikas Gandhe, Helicoid Stair Analysis by Semiloof Beam Element for Different Loadings, International Journal of Civil Engineering and Technology, 11(3), 2019, pp. 140-145.

https://iaeme.com/Home/issue/IJCIET?Volume=11\&Issue=3

\section{INTRODUCTION}

Structural members are designed for strength, safety and economy .'To achieve an economy, it is essential to know an exact behavior and analysis of structures for different loading and various boundary conditions of. For simple determinate structures ,the stress distribution can be provided by well known analytical methods But analysis of curved structures was complicated for different loading and boundary conditions. It creates complications in the analysis due to interaction of inplane and bending stresses It is therefore preferable to select some numerical method to obtained required solutions within the required engineering accuracyFinite Element Method is one of the most popular tool to analyses the complicated 
structures , due to advancement in engineering field An availability of fast running computers , now a days ,it saves energy and time of engineers with .great engineering accuracy .The semiloof beam element is probably the most efficient tool, for analyzing the highly curved structures. Accurate results are predicted for nontrivial geometric and loading configurations

As spatial structure, the helical staircase was considered for analysis and design with helix angle of 90 degree, floor height $=3.2 \mathrm{~m}$ and the waist slab thickness $=200 \mathrm{~mm}$. This staircase was analyzed for restrained boundary conditions. And different loading pattern . In this paper four different types of loading were applied. (1)U D L over the entire length (2) U D L over bottom half length (3) U D L over bottom half length (4)Point loads at quarter length of staircase The whole staircase was analyzed in six equal curved elements considering 13 nodal points with total, 72 degree of freedom

\section{BEAM ELEMENT}

The basic uncondensed configuration, showing 21 degree of freedom were shown in figure no 1 . Rotations at two loof nodes, situated at $\xi= \pm 1 / \sqrt{ } 3$ are in local directions, while other variables are in global directions.

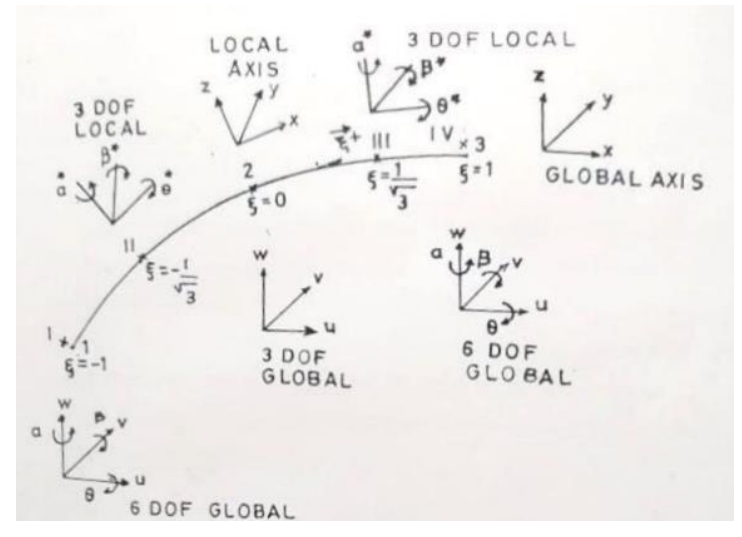

Fig -1 : Nodal configuration

\subsection{Displacements}

$\{\delta\} \mathrm{e}=[\mathrm{u} 1, \mathrm{v} 1, \mathrm{w} 1, \mathrm{u} 2, \mathrm{v} 2, \mathrm{w} 2, \mathrm{u} 3, \mathrm{v} 3, \mathrm{w} 3] \mathrm{T}-----9 \mathrm{dof}$

\subsection{Rotation}

$\{\Omega\} \mathrm{e}=\left[\Theta 1, \beta 1, \alpha 1, \Theta 2, \beta 2, \alpha 2, \Theta 3, \beta 3, \alpha 3, \alpha 4, \beta 4,{ }^{\circ} 4\right] \mathrm{T}----12 \mathrm{~d}$ o f

Suffix 1,2,3, in displacement, denote, denote corner and mid side

nodes at $\xi=(-1,0,+1)$ For inplane action $1,2,3,4$ denotes rotations at $(-1,-1 / \sqrt{ } 3,+$ $1 / \sqrt{ } 3,+1)$. The superscript $*$ denote local variables in a mixed nodal configuration with global direction This 21 degree of freedom are sufficient to define axial forces ,transverse shears, bending and torsional behavior of said curved beam. The four rotations $\beta 2, \alpha 2$, and $\beta 3, \alpha 3$ are condensed by static condensation method ,to obtain the curved beam of 17 degree of freedom . The use of higher order isoparametric elements which satisfies the continuity of displacements, slope and curvature inside the element boundaries under reduced integration technique ,has played a vital role in analyzing curved structures. The stiffness matrix ,once generated, will be used to operate on any number of loading arrays

\section{METHODOLOGY}


The helicoid stair case with 90 degree helix angle,3.2 $\mathrm{m}$ floor height, having $200 \mathrm{~mm}$ waist slab thickness was analyzed to predict the displacements, force resultants and moment resultants for different four types of loadings (1)Uniformly distributed load $5 \mathrm{kn} / \mathrm{m}$ over the entire center line length of stair case (2) Uniformly distributed load $5 \mathrm{kn} / \mathrm{m}$ over the entire bottom half length of stair case. i e for element 1 to 3 (3) Uniformly distributed load of 5 $\mathrm{kn} / \mathrm{m}$ over the entire top half length of stair case. i e for element 4 to 6 (4) Point loads $1 \mathrm{kn}$ at quarter lengths. Top and bottom supports were restrained in translation as well in rotation also . Other parameters selected to analyze the stair case were dealt as under .Inner radius : $500 \mathrm{~mm}$ , Outer radius : $1500 \mathrm{~mm}$,Width of stair case :1000 mm n/mm^2Waist slab thickness : 200 $\mathrm{mm}, \mathrm{E}: 0.12 \times 10^{\wedge} 5 \mathrm{n} / \mathrm{mm}^{\wedge} 2 \mathrm{G}: 0.5217 \times 10^{\wedge} 4 \mathrm{n} / \mathrm{mm}^{\wedge} 2$, Area of cross section $: 2 \times 10^{\wedge} 5$ $\mathrm{mm}^{\wedge} 2$, Poissons ratio :0.15, Unit weight of concrete : $24 \mathrm{Kn} / \mathrm{m}^{\wedge} 3$.Using M- 20 and Fe 415 ,the helical stair case was analyzed The results for displacements ,force resultants, moment resultants were obtained and shown in graphically as well as in a tabular form .

\section{OBSERVATIONS}

All the resultants thus obtained were shown graphically. The displacements in $\mathrm{U}, \mathrm{V}$ and $\mathrm{W}$ for all four types of loads were shown in fig no 2,3,4 respectively.

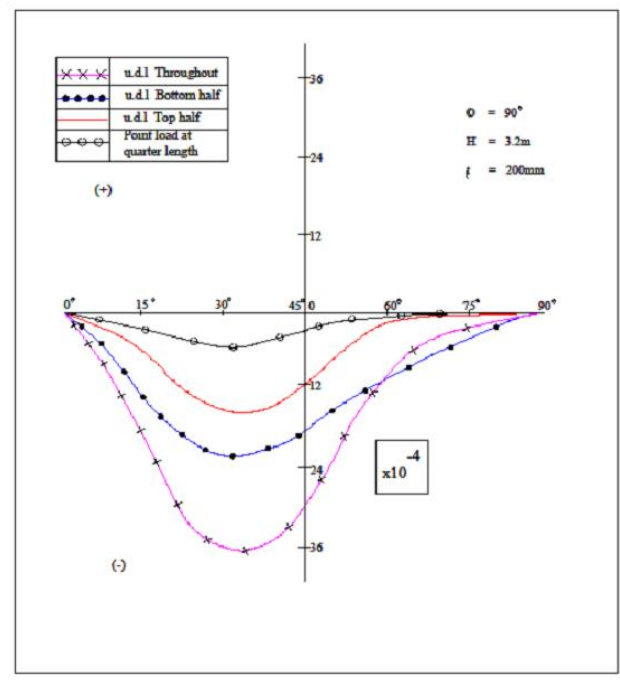

Fig -2: Displacement in ' $U$ ' Direction in $\mathrm{mm}$.

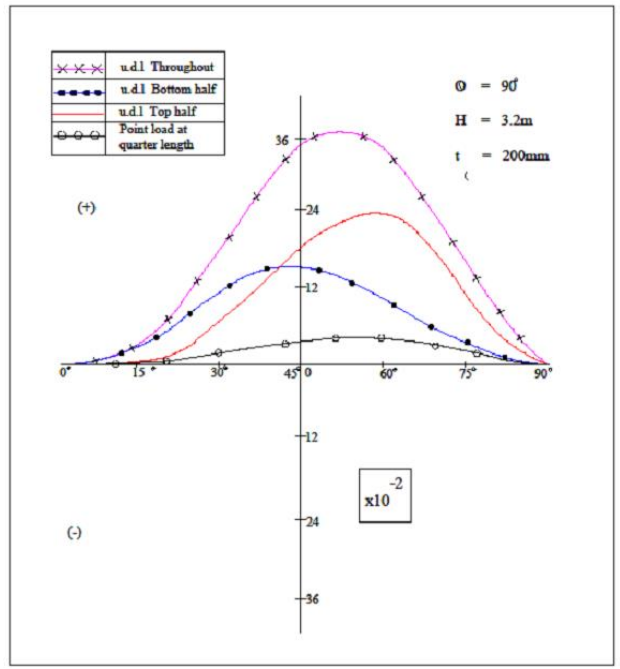

Fig -3 : Displacement in ' $\mathrm{V}$ ' Direction in mm 


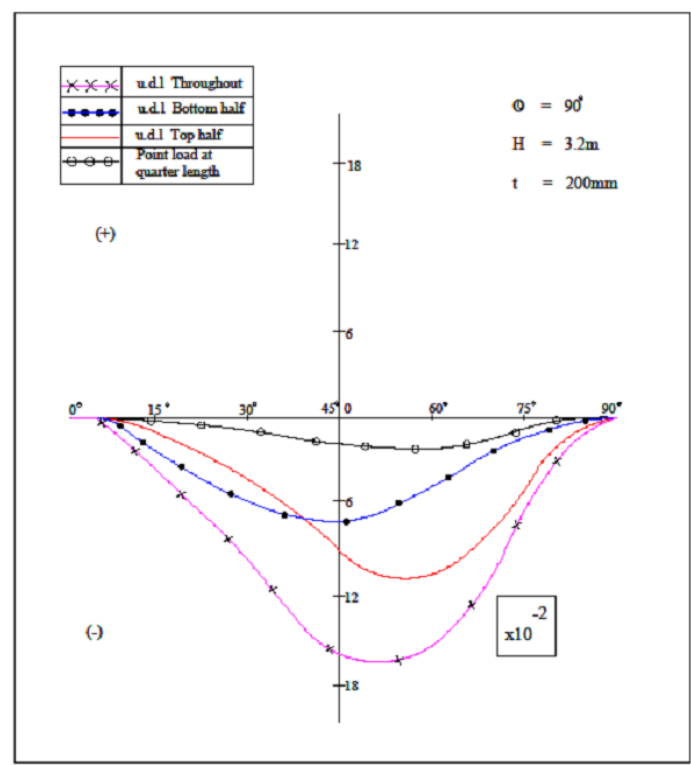

Fig -4: Displacement in ' $\mathrm{W}$ ' Direction in $\mathrm{mm}$.

Fig no 5, 6 and 7 indicate stress resultants as Fx ,Fxy and Fxz graphically .

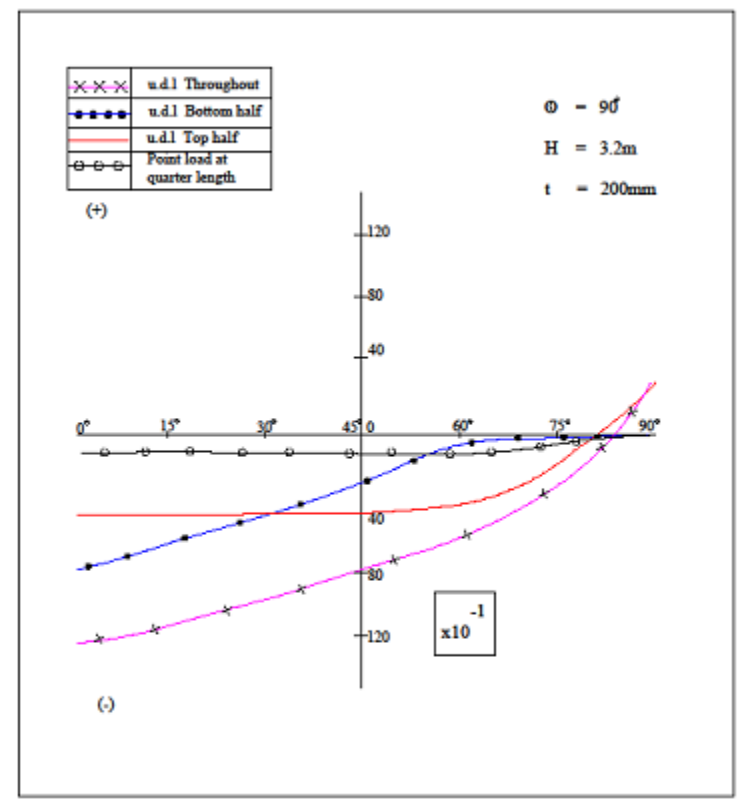

Fig -5 : Force Resultant "Fx" in $\mathrm{KN}$

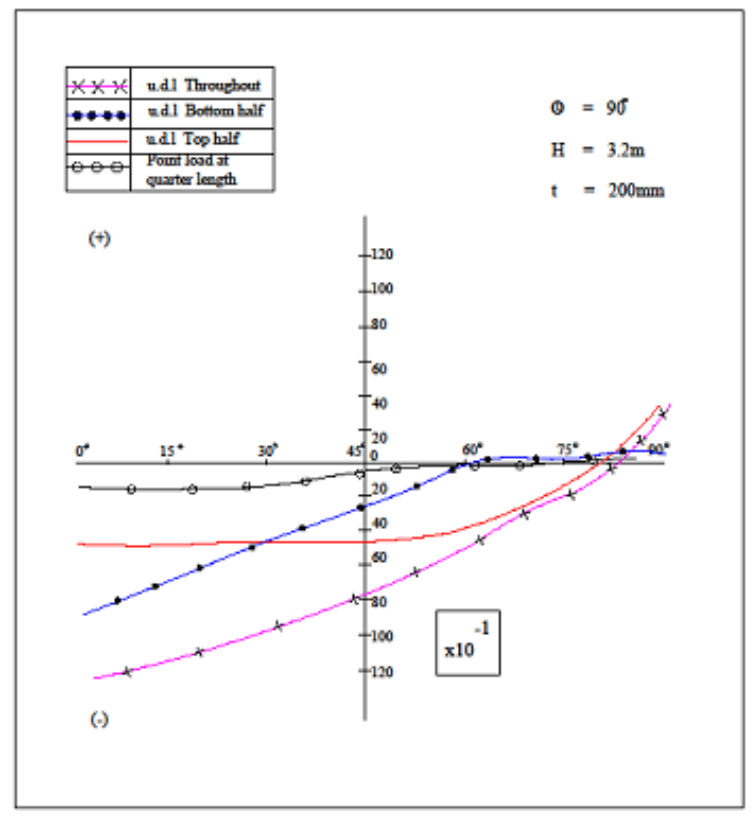

Fig -6: Force Resultant "Fxy" in KN 


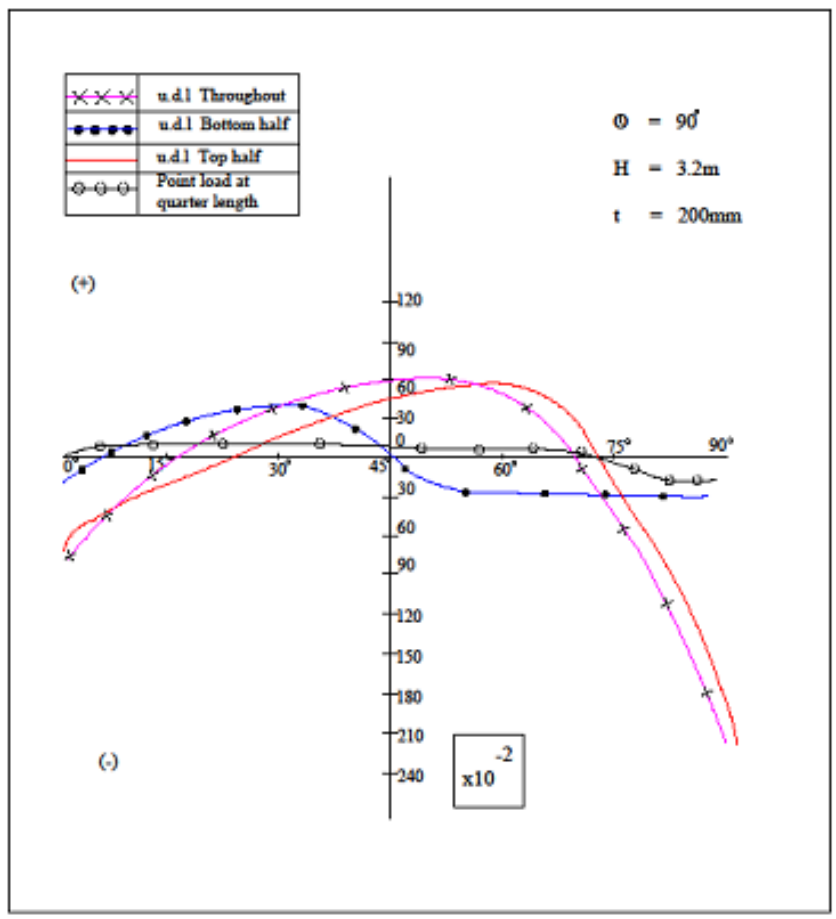

Fig -7 : Force Resultant "Fxz" in KN 10

Similarly ,all the moment resultants as Mxy, Mxz and Tor were shown in fig no 8,9 and

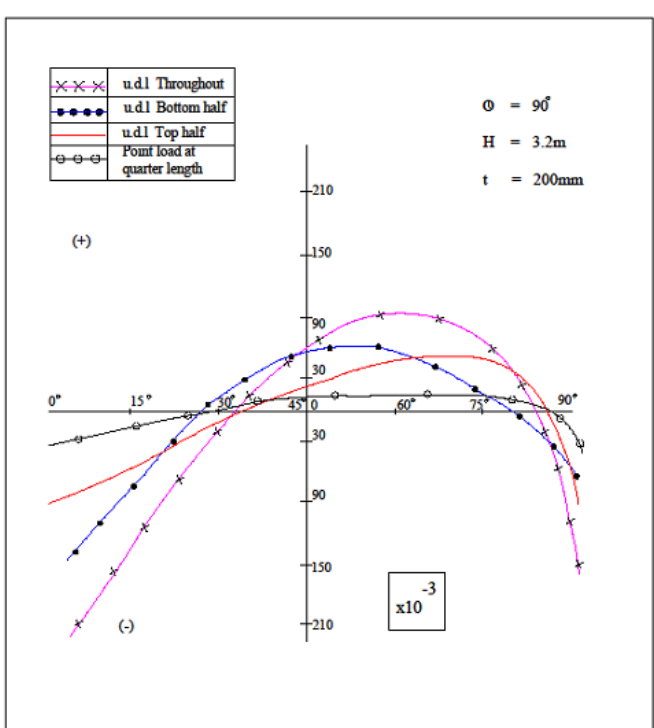

Fig -8 : Moment Resultant "Mxy" in KNM

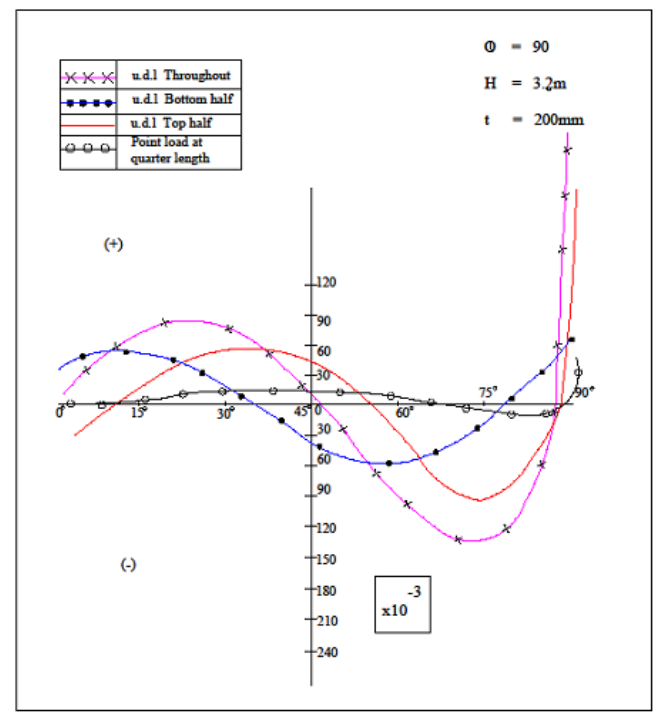

Fig -9 : Moment Resultant "Mxz" in KNM 


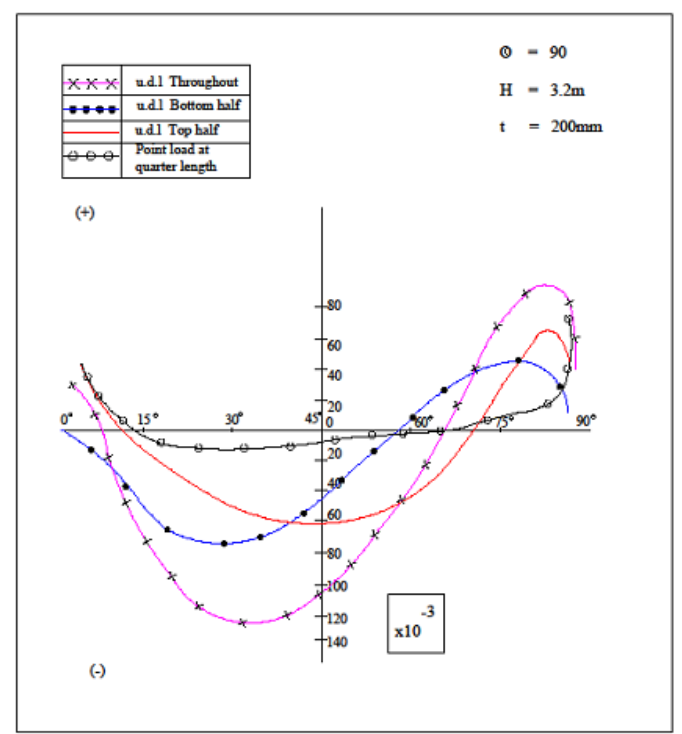

Fig -10 : Moment Resultant "TOR" in KNM

The salient values for displacements, force resultants and moment resultants were shown in tabular form through table no 1.

\begin{tabular}{|c|c|c|c|c|}
\hline S.No & Particulars & Symbol & Magnitude & Locations \\
\hline & & $\mathrm{U}$ & $-0.368 \times 10^{-3} \mathrm{~cm}$ & $35^{0}$ from bottom support \\
1. & \multirow{2}{*}{ Displacements } & $\mathrm{V}$ & $+0.365 \times 10^{-2} \mathrm{~cm}$ & $15^{0}$ from center towards top support \\
& & $\mathrm{W}$ & $-0.175 \times 10^{-2} \mathrm{~cm}$ & $30^{0}$ from top support towards support \\
\hline & & $\mathrm{F}_{\mathrm{x}}$ & $-0.12 \times 10^{+4} \mathrm{Kg}$ & At bottom support \\
2. & \multirow{3}{*}{ Force resultants } & $\mathrm{F}_{\mathrm{xy}}$ & $-0.4 \times 10^{+3} \mathrm{Kg}$ & At bottom support \\
& & $\mathrm{F}_{\mathrm{xz}}$ & $-0.71 \times 10^{+2} \mathrm{Kg}$ & At top support \\
\hline & & $\mathrm{M}_{\mathrm{xy}}$ & $-0.225 \times 10^{+5} \mathrm{Kgcm}$ & At bottom support \\
& & $\mathrm{M}_{\mathrm{xz}}$ & $+0.89 \times 10^{+4} \mathrm{Kgcm}$ & At Top support \\
& \multirow{3}{*}{ Moment resultants } & $\mathrm{T}_{\mathrm{OR}}$ & $-0.46 \times 10^{+3} \mathrm{Kgcm}$ & $35^{0}$ from bottom support \\
\hline
\end{tabular}

\section{CONCLUSIONS}

Semiloof beam element is capable of producing accurate results with less number of elements, within the permissible engineering limits

Although, helical stair case is highly curved structures, still, if both the supports are restrained in translation as well as in rotation, the magnitude of torsional moment is negligible

Maximum values for $U$ displacement,due to all four types of loadings, is at $1 / 3$ of total length of case helical stair case

Maximum displacement in $\mathrm{V}$ and $\mathrm{W}$ direction, appears between 45 and 60 degree.

For all the four types of loadings, mentioned above, maximum values of moment resultant, Mxy, appears at bottom support

For all the loadings, mentioned above, maximum moment Tor is observed between $30-45$ degree

\section{REFERENCES}


[1] IRONS.B.M. and AHMAD.S.,"Technics Of Finite Element "Ellis Harwood Limited ,1980.

[2] SHRIVASTAVA .N . K .," Study Of Shell Junctions and Openings". Ph D Thesis ,University Of Roorkee.1981.

[3] Zienkiewics,O. C.,"The Finite Element Method “,McGraw Hills Limited,1979.

[4] Iron . B .M., "The Semiloof Beam Element “,Finite Element for thin shell and Curved Members",ch . 11 (ed) ,John Willey and Sons, Newyork, 1976.

[5] Desai,C. S.and Abel,J.P.,"Introduction to the Finite Element Method", Litton Educational Inc, New York , U.S.A.,1972. 